\title{
A Study on the Culture Tourism Development ---- A case Study of Linyi
}

\author{
ShouYanMiao ${ }^{1,2}$ \\ ${ }^{1)}$ School of Liberal Arts, Linyi University, Linyi, Shandong, China. \\ ${ }^{2)}$ School of Liberal Arts, NanJing University, NanJing, JiangSu, China.
}

\begin{abstract}
Culture tourism is a kind of new research trend and the way of travel in the academic and practical operation, etc. This paper study the conception of Culture tourism and its reasons causing. Furthermore takes Linyi as an example and analyzes its category. The paper takes the relevant measures to promote the development of cultural tourism in Linyi City: to strengthen the government leading force for cultural tourism effect, to increase the intensity of cultural tourism attractions development and protect cultural tourism resources, to promote the intensive development of Linyi cultural tourism, to strengthen the publicity of cultural tourism and develop cultural tourism marketing, to create a good cultural atmosphere with citizen participation, etc.
\end{abstract}

Keywords-Linyi, Cultural tourism, Development measures

\section{临沂文化旅游发展研究}

\author{
苗守艳 ${ }^{1,2}$ \\ 1) 临沂大学文学院文学院, 临沂, 山东, 中国 \\ 2) 南京大学文学院, 南京, 江苏, 中国
}

摘 要 文化旅游是学术和实践操作等层面一种新的研究趋势和旅游方式。研究中首先探讨了文化旅游的涵义和它兴起的原因、 特征等, 并以临沂文化市旅游为例, 研究了文化旅游的类别; 根据临沂市文化旅游现状以及优劣势、面临的机遇等情况, 进而提出了 临沂市文化旅游进一步发展需要采取的措施: 增强政府主导能力; 加大景点开发力度和文化资源保护; 推进临沂文化旅游集约发展; 加强文化旅游宣传力度; 打造临沂文化旅游品牌。

关键词＼cjkstart临沂，文化旅游，发展措施

\section{1. 引言}

文化是旅游的灵魂, 旅游是文化的载体。文化是提高 旅游内涵、提升旅游素质的重要条件, 文化和旅游是一种 相成相辅、共同促进的关系。随着旅游业的不断发展, 加 之新的休假制度的完善, 旅游者在旅游过程中越来越注重 精神的享受, 对旅游产品文化的内容、内涵的品位要求更 高, 纯粹经济型的旅游业正在逐步向文化型的旅游经济产 业发展, 文化旅游以特色的文化资源和吸引力, 正成为当 今世界旅游业发展的新潮流, 呈现出强大的生命力和空前 的发展空间。

我国各地区文化旅游出现欣欣向荣的景象, 而其中, 临沂市的文化旅游最具发展前景。临沂具有丰富的文化资 源, 是著名的文化名市, 全市共有各种自然与人文旅游资
源 8 大类 30 多个亚类等。虽然我市有发展文化旅游的优越 条件，但也存在着政府对文化旅游的重视度低、文化旅游 基础设施薄弱以及民众文化旅游意识淡薄等问题, 文化旅 游发展还比较滞缓, 没有形成品牌效应。立足于前人研究 的基础上, 进一步抓住机遇, 加大政府对文化旅游的重视 度、完善基础设施建设等, 大力发展临沂市的文化旅游。 依托于优越的人文资源条件走向全省、全国、全世界, 将 成为发展临沂市旅游业核心竞争力的关键所在。

\section{2. 文化旅游的涵义}

\section{1 文化旅游的含义}

文化是旅游景观吸引力的基础和源泉, 是旅游业发展 的关键所在, 文化旅游的产生, 正是抓住了旅游业的本质 
内容, 使旅游业发展的深层次东西被直接表露了出来, 文 化旅游是当今旅游消费的发展趋势和主旋律 [1]。文化旅 游资源 [2]就是指凡是能够吸引旅游者产生文化旅游动机, 并可能被利用来开展文化旅游活动的各种自然、人文客体 或其他因素。文化旅游资源既有物质的, 也有非物质的, 以“文化旅游”方式来强调旅游活动和行为中的文化内涵, 是学术和实践操作等层面一种新的研究趋势和旅游方式, 这也是旅游发展从低级到高级阶段的必然结果。

从总体上说, 文化旅游 [3] 是指旅游者作为旅游主体, 借助旅游中介和旅游目的地等外部条件, 通过对信仰、精 神、知识、艺术、语言、风俗、习惯、历史、传说和自然 遗产、人文遗产等旅游客体的某一类或几类旅游资源的观 察、鉴赏、体验和感悟, 从而得到的一种文化享受和收获 的旅游活动。它包括历史文化游、现代文化游和民族民俗 文化游三大部分, 建筑、宗教、艺术、体育、科普等都可 以归入其中。

\section{2 文化旅游的产生原因}

从需求方面来看, 人不仅追求物质生活, 更有精神需 求。物质生活日益丰富, 文化旅游需求日渐高涨, 各国家 和地区市场经济高度发达, 带薪假期制度和较高的可支配 收入让旅游者在观光旅游外愿意选择更加休闲放松的度假 旅游和专项旅游等文化旅游。从供给方面来看, 与观光旅 游者、休闲旅游产品相比, 文化旅游者一般在旅游目的地 停留时间长过普通的观光旅游者, 所以和传统旅游相比, 文化旅游的花费更高, 这便极大的推动了经济的发展。文 化旅游所带来的高收益, 使得旅游产品提供商愿意提供更 具针对性的文化旅游产品从而吸引文化旅游者, 文化旅游 竞争市场越来越激烈, 促使提供商和文化旅游经销商更加 的注重文化旅游市场的发展, 提高文化旅游产品的专门化 水平。

\section{3 文化旅游的特征}

（1）文化旅游的综合性强

文化旅游是不同于观光旅游的新的旅游方式, 文化旅 游包括旅游者运用美学、旅游学、社会学等多门学科去感 受这一旅游活动, 一次文化旅游不仅是历史文化旅游产品 的体验, 也包括风情、民俗等文化旅游产品的体验, 它是 一个综合性极强的文化活动, 它是旅游体验者、旅游中介 和旅游景观的综合统一体, 它也体现了“食、住、行、游、 购、娱”旅游活动六方面的统一 [4]。

（2）文化旅游的地域性显著

文化旅游是感受某一景区、某一地区的文化, 它的地
域性非常显著, 如山东的鲁文化和齐文化, 鲁文化以内陆 济宁曲阜地区为特色, 重礼重农, 有着封闭性, 而齐文化 以山东沿海一带的地区为代表, 重工商有着开放性的显著 特点。沂蒙山区的临沂文化因为其地理位置和历史发展决 定了它的地域特色: 辛勤勇敢、艰苦朴素、热情好客、团 结奋斗。这种地域性具有独特性和不可复制性。

\section{（3）文化旅游的情感性强烈}

文化旅游充满了强烈的情感色彩, 这在旅游体验文化 中表现的最为明显。旅途中总会有情感伴随旅游者, 欢乐 或是痛苦; 可能是审美的或非审美的, 酸甜苦辣, 一言难 语。一次文化旅游的发展史, 其实也是一次情感发展史。 翻开一本游记, 便能强烈的感受到作者情感性的这一点。

\section{3. 临沂市文化旅游的主要类别}

将图与表放在该栏的顶部或尾部, 避免将它们放在一 栏的中间, 图与表的宽度尽量不要超过栏宽。确实大的图 或表可以跨栏放置。图题应该居中放在图的下面, 表题应 该居中放在表的上面。避免将图或表放在提及的段落之前。 3.1“孝”文化旅游 中国人世代推崇孝道, 至今流传着二十 四孝的传说, 其中七孝就在临沂, 分别是: 仲由负米 (子 路)、鞭打芦花 (闵子骞)、曾参养志 (曾参)、老莱斑衣 (老 莱子)、郯子养鹿 (郯子)、王哀泣坟( 王哀)、王祥卧冰(王 祥)。2012 年 9 月 12 日举行了中国临沂“孝”文化节, 它以“羲 之故里, 孝友传承”为主题, 着力打造三圣 (书圣王羲之、 孝圣王祥、友圣王览）文化品牌, 期间将在孝友祠举办三 圣祭拜仪式、“感恩孝河”精彩文艺演出、孝老爱亲道德模 范颁奖、书画名家书孝活动等丰富多彩的配套活动。“孝” 文化与临沂旅游业相融合, 渗透到各地区民众的心中, 让 民众有了探索临沂的欲望, 来临沂旅游, 促进临沂旅游业 蓬勃发展, 带动相关行业发展, 繁荣临沂的社会经济, 共 建和谐新社会。

\section{2 书圣文化旅游}

在临沂历代所出的名人中, 以书圣王羲之最为世人所 崇, 故人们又习惯称临沂为“羲之故里”。书圣王羲之, 字 逸少, 今临沂市人。王羲之自幼酷爱书法, 真、草、隶、 管俱佳, 其书艺师承钟繇, 变革古法, 创立今体, 把今体 书法推向了文人书法的极致, 其中书圣王羲之的字被梁武 帝称之为“体势雄逸”如“龙跳天门, 虎卧风阙”, 可见其书 法艺术造诣之高。与其子王献之, 在我国书法史上羊称“二 王”。十届中国临沂书圣文化节展示了“中国临沂. 书圣故里” 的书法文化成就。书圣文化与旅游业相促进, 把“中国临 沂. 书圣故里”的品牌叫响全国, 把中国书法文化推向世界, 
传承中国优秀的书法文化, 来临沂感受书圣文化、体验书 圣文化, 从而促进临沂旅游业及整个临沂市的文明发展。

\section{3 红色文化旅游}

沂蒙山区作为山东革命根据地的中心地区, 在抗日战 争和解放战争中共计发生过万余次的大小战斗, “乡乡有红 嫂，村村有烈士” [ 是沂蒙人民投身革命、支持前线斗争的 真实写照。华东革命烈士陵园、孟良崮旅游区等是感受沂 蒙红色文化的最佳地方。沂蒙精神展、国庆六十周年献礼 电影《沂蒙六姐妹》、大型水上实景歌舞演出《蒙山沂水》 等都在歌颂宣传沂蒙红色文化。沂蒙精神的形成意味着红 色文化在沂蒙区域社会获得了主导地位、成为引领沂蒙山 区社会发展、塑造沂蒙人民精神风貌的力量条件, 是建设 “旅游经济强市、红色旅游名市”为目标的关键所在。

\section{4 兵学文化旅游}

临沂的“文蹈”是指上面提到的以书圣王羲之等文人为 代表, 而“武略”就是指以 《孙子兵法》、《孙膑兵法》为主 要内容的银雀山汉墓竹简以及著名的军事家诸葛亮为典型 代表。1972 年出土的《孙子兵法》被誉为“兵学圣典”、“世 界古代第一兵书”, 其战略思想, 堪称一大智举。其中三十 六计流传至今。“智圣”诸葛亮, 字孔明, 号“卧龙先生”, 三国时期著名的军事家。“空城计”是他运用攻心之术、以 少胜多的典型事例; 他的智慧对于今天的领导者管理员 工、经营公司都有深深地借鉴意义。

\section{4. 临沂市文化旅游发展的对策与措施}

\section{1 进一步加大政府对文化旅游的主导力作用}

旅游业是涉及面广、带动性强的综合性产业, 而文化 旅游作为新的旅游发展方式更具有复杂性、综合性和关联 性, 发展文化旅游业涉及到多个部门、多个区域、多个行 业的方方面面, 政府主导作用十分重要。近年来, 我市政 府在发挥“政府主导型”作用方面还不足, 尤其是“孝”文化 旅游中的主导力作用, 因此, 政府要加大对 “孝”文化旅游 等文化旅游的支持力度, 制定相关的法律章程, 消除文化 旅游管理体制的弊端, 进一步加大政府对“孝”文化旅游资 金的投入, 完善文化旅游的各项基础服务设施, 加快我市 文化旅游的发展。

\section{2 加大文化旅游景点开发力度和保护文化旅游资源}

在众多类型的旅游资源中, 文化类旅游资源开发难度 较高, 文化旅游资源的开发, 需要进行提取、浓缩和概括, 也需要寻找较好的表现形式和依托, 因此, 在开发文化旅
游资源时, 要更加细致, 注意避免雷同化的问题, 如对临 沂书圣文化旅游资源中古遗迹的重复兴建和注重表面装饰 等不良问题的改善, 进行深度的良性开发; 还要坚持严格 保护和科学利用相结合的原则, 保护文化旅游资源第一、 开发文化旅游资源第二, 把发展文化旅游和保护文化旅游 资源统一起来, 坚持文化旅游的可持续发展原则。

\section{3 推进临沂文化旅游集约发展}

加快临沂文化旅游由粗放型向集约型发展转换, 是提 高临沂文化旅游竞争力的根本途径。一方面, 要培育大型 文化旅游龙头企业, 要整合文化旅游资源, 做大做强临沂 文化旅游集团等国有文化旅游公司, 着力建立和发展一批 核心竞争力强、信誉好的特色文化旅游商品企业, 借鉴沂 水发展旅游业的良策, 创建优秀而又有影响力的知名企业 [5]; 另一方面, 进行文化资源整合, 把我市的“孝”文化 资源、书圣文化资源、红色文化资源和兵学文化资源统一 整合起来, 以书圣文化旅游为核心, 其他类文化旅游协作 联合, 推进临沂文化旅游业的集约式发展。

\section{4 加强文化旅游宣传力度, 开展文化旅游营销}

旅游宣传是文化旅游发展的前提条件, 目前, 临沂市 虽然拥有较多较好的文化旅游产品, 但是依然处于很少被 知晓的层面上, 知名度低。因此, 做好宣传工作, 提高文 化旅游产品的知名度是其发展的关键。第一方面, 坚持政 府主导整体形象宣传与企事业推销相结合, 旅游行业宣传 与其他相关部门相结合的办法等, 形成全方位、多层次的 立体宣传营销体系, 如济南的年货展销会等形式来宣传济 南的文化旅游一样, 通过举办展销会等活动来宣传临沂, 促进临沂书圣文化等文化旅游的持续性发展; 第二方面, 鉴于曲阜市发展孔子文化的良策, 我们临沂也要尽可能的 建造羲之学院等, 学习书圣文化, 加大宣传力度, 发展书 圣文化旅游借鉴沂水发展文化旅游的措施, 进行捆绑式营 销, 统一于大的文化旅游发展公司, 统一管理, 统一营销, 提升知名度, 从而推进临沂文化旅游的发展。

\section{5 打造临沂文化旅游品牌}

旅游局和相关部门要立足于临沂市悠久的人为历史 和自然风光资源的开发情况下, 在打造了以“绿色沂蒙、红 色风情、文蹈武略、地质奇观”为主题的旅游产品体系和一 批特色旅游精品线路的基础上, 再深入开发文化旅游资源, 塑造临沂文化旅游特色品牌, 特别是“红色风情、文韬武略” 这两大主题品牌突出鲜明, 立足于临沂浓郁而悠长的红色 文化和书圣文化、“孝”文化等人文特色, 以文兴旅, 以旅 
促文, 从而使得临沂文化旅游品牌更加具有吸引力和竞争 力, 推动临沂文化旅游产业融合发展。

\section{5. 结束语}

文化旅游是一种新的旅游形式, 随着我国经济的发 展和人们生活水平的提高, 文化旅游将会越来越被人们 所接受和需要。在全体沂蒙儿女的努力下, 在悠久而著 名的历史文化基础上, 文化旅游发展的前景很广阔、很 光明, 它会提升临沂市的文化鬼力、促进临沂经济的快 速发展、完善市民文化素质和提高省内经济名市的品牌 地位。

\section{参考文献(References)}

[1] $\mathrm{Xu}$, Chunhua. Development and Thinking on Culture Tourism of $\mathrm{Wu}$ Weishi. Journal of Chongqing University of Science and Technology (Social Sciences Edition), 2010, (8):63-67.

[2] LiYun. A Preliminary Research on the Development of culture tourism resources --A Case Study of Zhejiang Province. HangZhou: Zhejiang University, 2008.

[3] Wang Mingxing. Culture Tourism: Management • experience • pattern. TianJin: NanKai University Press, 2008:10-11.

[4] PengKui. A Study on the Culture Tourism of ZiGong Development. SOCIAL SCIENCES REVIEW,2010,25:175-177

[5] GguoMeibin. Development Ideas and Countermeasures of Sichuan Cultural Tourism Industry. Enterprise Economy, 2012, 11:120-123. 